\title{
The Importance of Measuring Ultrafine Particles in Urban Air Quality Monitoring in Small Cities
}

\author{
Ivan Notardonato ${ }^{A}$, Maurizio Manigrasso ${ }^{B}$, Luigi Pierno ${ }^{C}$, Gaetano Settimo ${ }^{D}$, \\ Carmela Protano ${ }^{\mathrm{E}}$, Matteo Vitali ${ }^{\mathrm{E}}$, Vincenzo Mattei ${ }^{\mathrm{F}}$, Stefano Martellucci ${ }^{\mathrm{F}}$, \\ Cristina Di Fiore ${ }^{\mathrm{A}}$, Paolo BocciaA ${ }^{\mathrm{A}}$, Pasquale Avino ${ }^{\mathrm{A}^{*}}$ \\ Received: December 15, 2019 | Revised: December 28, 2019 | Accepted: December 28, 2019 \\ DOI: $10.5937 / g p 23-24447$
}

\begin{abstract}
The air quality monitoring is based on the determination of some gaseous pollutants and PM10 and $\mathrm{PM}_{2.5}$. Recent studies have reported the importance of the determination aerosol fraction below $1 \mu \mathrm{m}$ both for the dynamic of the airborne and for the public health issue. This paper would like to investigate the importance of this fraction in the air quality monitoring. Further, a particular focus will be devoted the role of the Ultrafine Particles, i.e. particles below $100 \mathrm{~nm}$, in the aerosol formation and in the human exposure. Two case studies will be presented and discussed on how the submicron particles can be determined and interpreted their role. In the first case, the measurements will be performed in downtown Rieti, city located in central Italy, $100 \mathrm{~km}$ North from Rome, with the scope to draw the behavior in relationship to the emission flexes. In the second scenario, the personal exposure of pedestrians will be investigated in Venafro, a small city located $150 \mathrm{~km}$ South-East Rome, by means of measuring PMx, total submicron fraction, different aerosol dimensional sizes in the range 5-360 nm along with the total Volatile Compounds. The different sources and contributions affecting the aerosol levels in the two areas will be investigated and extensively discussed as well as the role of the such particles in the aerosols science.
\end{abstract}

Keywords: Aerosol; Particulate Matter; Ultrafine particles; Level; Dynamic; Instrumentation; Source; Urban; Air Quality; Monitoring; Exposure; Health effects

\section{Introduction}

Air pollution exposure represents a well-known risk to human health (Johannson et al., 2015) and ecosystems (Wright et al., 2018; Ssebugere et al., 2019). A strong focus on atmospheric air pollution has been developed worldwide which has led to a significant reduction of some contaminants in the atmospheric environment. The starting point of this approach is that the population, especially in urban areas, spends most of the time (up to $90 \%$ ) indoors (Carrer et al., 2000; Avino et al., 2003; Kelly \& Fussell, 2019).

Studies indicate that indoor air quality is influenced by outdoor air and confirm the importance of outdoor air in determining indoor air quality (WHO, 2013a; WHO, 2013b; Lia et al., 2019). Ventilation has

\footnotetext{
A Department of Agricultural, Environmental and Food Sciences (DiAAA), University of Molise, via De Sanctis, I-86100 Campobasso, Italy

B DIT, INAIL, via IV Novembre 144, I-00187 Rome, Italy

C ARPA Molise, via U. Petrella 1, I-86100 Campobasso, Italy

D Italian Institute of Health, viale Regina Elena 299, I-00161 Rome, Italy

E Department of Public Health and Infectious Diseases, University of Rome "La Sapienza", p.le Aldo Moro 5, I-00185 Rome Italy

F Laboratory of Experimental Medicine and Environmental Pathology, Polo Universitario di Rieti, Sabina Universitas, I-02100 Rieti, Italy

* Corresponding author: Pasquale Avino; e-mail: avino@unimol.it; Telephone: +39-0874-404 631
} 
a strong influence on both indoor particulate matter and indoor gas concentrations. The lower in door/outdoor (I/O) particle ratios were found under closed window conditions, whereas higher I/O ratios were achieved in well-ventilated environments (Leung, 2015). In addition, indoor and outdoor pollutant concentrations were correlated, and more than $75 \%$ of daily indoor variations are explained by outdoor ones (Cyrys et al., 2004).

The importance of the topic is demonstrated by some data:

- a person breathes about $15 \mathrm{~kg}$ of air per day, while he consumes about $1 \mathrm{~kg}$ of food per day, $2.5 \mathrm{~kg}$ of liquids per day;

- the indoor environment can be 50 times more polluted than outdoor;

- population spend about $90 \%$ of their life in indoor environments;

- the PM1 transports mutagenic chemical elements inside the buildings;

- each person inhales more than 25 million particles by each breath;

- patients in hospital healthcare settings benefit from improved air quality;

- particles smaller than $1 \mu \mathrm{m}$ can reach the pulmonary alveoli;

- ultrafine metal particles have been found in the brain (Maher et al., 2016; Manigrasso et al., 2019a);

- particles less than $0.1 \mu \mathrm{m}$ can reach all the human organs through the blood.

Particles of different sizes can show different characteristics during the interaction between indoor and outdoor air. Monn et al. (1997), for example, studied the indoor-outdoor relationship of particulate matter (PM) with different aerosol sizes in 17 houses in Switzerland with natural ventilation. In houses without indoor sources and with low anthropogenic activities, the I/O ratio of $\mathrm{PM}_{10}$ was about 0.7. Among indoor sources, smoking is the most dominant factor and can increase the I/O ratio to $>1.8$. On the other hand, human activities are an important factor contributing to high I/O ratios. Jones et al. (2000) found that I/O ratios are greater for fine particles than coarse particles, indicating greater penetration of fine particles or greater internal deposition of coarse particles. Diapouli et al. (2008) measured indoor and outdoor particulates in schools with ventilation and found I/O ratios close to or greater than 1 for $\mathrm{PM}_{10}$ and $\mathrm{PM}_{2.5}$, but smaller than 1 for ultrafine particles (UFPs). However, similarly to other research results, they also observed very high $\mathrm{I} / \mathrm{O}$ ratios $(>2.5)$ when there were intense indoor activities such as human movement, smoke, etc. Massey et al. (2009) determined the indoor/out- door ratio of fine particles smaller than $2.5 \mu \mathrm{m}$ in residential homes located in central India and found that average I/O ratios for $\mathrm{PM}_{2.5}, \mathrm{PM}_{1.0}, \mathrm{PM}_{0.5}$ and $\mathrm{PM}_{0.25}$ were near or above 1 in houses on the roadsides and in rural areas, while they were found to be lower than 1 in urban areas. Chen \& Zhao (2011) examined the relationship between indoor and outdoor particles in the literature and found that very high $\mathrm{PM}_{2.5} \mathrm{I} / \mathrm{O}$ ratios (i.e. > 3.0) occur in the presence of smoke and internal combustion sources like a fireplace, whereas the low I/O ratios (i.e. $<1$ ) are strongly correlated to fewer internal sources, to the use of air filtration devices or to buildings with good insulation gaskets, particularly doors and windows.

The most recent studies reported in the scientific literature define, as more appropriate, the measurements for detecting lower particle size fractions. The term Ultrafine Particles (UFPs) refers to particles with an aerodynamic diameter of less than $0.1 \mu \mathrm{m}$ (100 $\mathrm{nm}$ ). This particle size is comparable to those of biological molecules, while such particles are larger than atoms and considerably lower than human red blood cells or human alveolar macrophages.

An important issue, connected to the physical UFP characteristics, is related to their size. In fact, the larger particles, due to gravity, are deposited on the ground in the immediate vicinity and within a short time, with respect to the emission point and time; on the contrary, the UFPs can travel long distances and remain suspended in the air for hours or days after the emission. However, they are unlikely to maintain their starting sizes, due to the high tendency to coagulate/accumulate. UFPs can derive from autovehicular traffic emissions (Avino et al., 2011; Marini et al., 2015), from the use of fuels used in different types of heating systems (Stabile et al., 2018; Jiang et al., 2019), as well as from the oil industry and other industrial processes (Fernández-Camacho et al., 2012; Borrow et al., 2018; Wang et al., 2018), including incineration and waste treatment plants (Buonanno et al., 2010, 2011; Buonanno \& Morawska, 2015;). In recent years, a growing number of studies have reported UFP concentration values expressed as the number of particles per cubic centimeter; in most cases, where the aerosol size distribution was reported, it was found that UFPs represented the most conspicuous part in terms of numerical concentration (Manigrasso \& Avino, 2012; Manigrasso et al., 2013). In a survey performed in Erfurt, Germany, the particle number counted was $73 \%$ of the UFPs, although they contributed only $1 \%$ of the mass concentration (Wichmann et al., 2009).

In general, aerodynamic factors predominate for particulates with diameters $>1 \mu \mathrm{m}$ and the relative deposition occurs by sedimentation (depending on 
gravity) or impact (direct collision of a particle with the epithelial surface), which in turn are influenced by characteristics of particle size and density. On the contrary, for particles with diameter less than $100 \mathrm{~nm}$ $(0.1 \mu \mathrm{m})$, the deposition occurs as a result of chaotic particle diffusion motions (Brownian motion) dependent only on the diffusion coefficient. Finally, aerodynamic and thermodynamic factors are relevant for diameters between $0.1 \mu \mathrm{m}$ and $1 \mu \mathrm{m}$. Studies show that the main UFP determinants are the number and the surface area and not the weight (Manigrasso et al., 2019b). This paper would like to point out the importance of an emerging pollutant, i.e. the Ultrafine Particles (UFPs), in urban air quality monitoring: for evidencing such issue the authors will discuss the data collected in two different sites located in Central Italy and characterized by different environmental conditions.

\section{Materials and Methods}

\section{Sampling sites}

Two different sampling sites have been considered in this study, both of them located in central Italy: the two sites are different for extension and population number, but they can be representative of the Italian leaving areas, over the big cities.

The first sampling has been performed in Rieti, a town stands on a small hilltop, commanding from the southern edge the wide Rieti valley, at the bottom of the Sabine hills and of Monti Reatini, including Mount Terminillo, with a population of 47,700 inhabitants (coordinates $42^{\circ} 24^{\prime} \mathrm{N} 12^{\circ} 52^{\prime} \mathrm{E}$; area $207 \mathrm{~km}^{2}$; elevation $405 \mathrm{~m}$ a.s.l.). The sampling site is located in downtown and is characterized by autovehicular traffic, i.e. cars and buses.

The second sampling has been performed across Venafro, a town in the province of Isernia, region of Molise (coordinates $41^{\circ} 29^{\prime} 4^{\prime \prime} \mathrm{N} 14^{\circ} 2^{\prime} 45^{\prime \prime} \mathrm{E}$; area $45 \mathrm{~km}^{2}$; elevation $222 \mathrm{~m}$ a.s.l.). It has a population of around 11,000 , having expanded quickly in the post-war period. The site is characterized by high heavy traffic, i.e. both cars, buses and trucks, and in its surroundings two main plants, i.e. a cement plant and an incinerator, are present over a large industrial area.

\section{Measurements}

According to both the sites and the scope, two different approaches were carried out.

In downtown Rieti a Fast Mobility Particle Sizer (FMPS, model 3091, TSI, Shoreview, MN, USA) was used (Figure 1). This instrument allows the particle determination and classification at high time-resolution (1 s) in the range $5.6-560 \mathrm{~nm}$ by means of the electrical mobility diameter. This equipment, operating at $10 \mathrm{~L} \cdot \mathrm{min}^{-1}$ for minimizing the UFP loss by diffusion, counts and classifies the particles in 32 size channels. The combination of features makes the FMPS spectrometer ideal for measuring the dynamic behavior of submicrometer particles over a wide range of applications, including particle formation and growth studies, indoor air-quality measurements, environmental research, urban canyon studies, and transient emission studies of stacks, boilers, wood burners, and much more. The measurements were carried out in July.

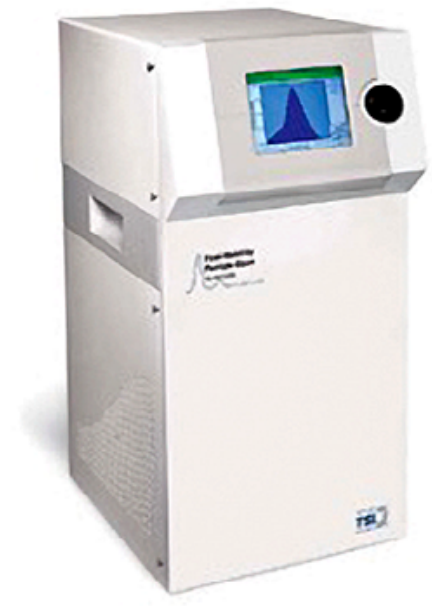

Figure 1. Equipment used in the Rieti campaign: Fast Mobility Particle Sizer, counting and size dimensional classification (electrical mobility diameter) 5.6-560 nm. Temporal resolution: 1 second

In the other site, Venafro town, the approach was totally different: the methodology was addressed for evaluating the exposure of a pedestrian walking through the town. For this aim a footpath covering almost the whole town was identified. A 30-min walking path was considered: in particular, four different areas can be identified on the selected path. The first and forth sections are along "SS6" and "SS85", the two main roads that connect Venafro with the highways and the industrial area, characterized by high heavy vehicular traffic density (cars, buses, trucks); the second one is in downtown at medium traffic density, basically local traffic, and the third section is a low vehicular traffic density. These paths allow to give an idea about the exposure of a pedestrian overall the town. In this site the approach was set up for taking different information respect the other scenario: portable instruments were used for determining particulate matter $(\mathrm{PM})$, submicron particles, ultrafine particles along with the measure of total Volatile Organic 

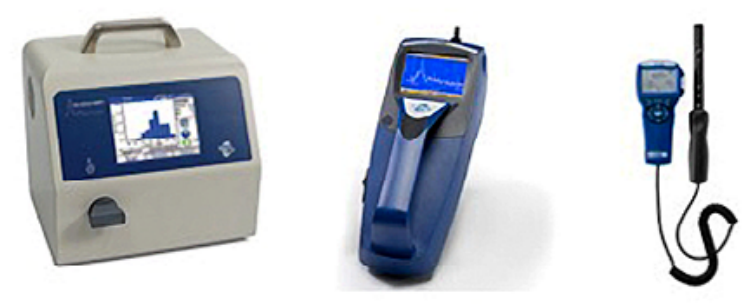

Figure 2. Mobile instruments used in the Venafro campaign: Nanoscan (left), DustTrakTM II aerosol monitor (middle) and Q-TrakTM Indoor Air Quality Monitors (right)

Compounds (VOCs), considered an index of the anthropogenic activities in an area (Manigrasso \& Avino, 2008) (Figure 2).

In particular, a DustTrakTM II Aerosol Monitor (model 8532, TSI), a handheld battery-operated, data-logging, light-scattering laser photometer, allowed a simultaneous measurement of $\mathrm{PM}_{1}, \mathrm{PM}_{2.5}, \mathrm{PM}_{4}$, or respirable fraction, $\mathrm{PM}_{10}$, and Total $\mathrm{PM}$ size fractions.

On the other hand, a NanoScan SMPS (model 3910, TSI), was also used for measuring particle number concentrations in the range $10-365 \mathrm{~nm}$ (divided in in thirteen size channels) by means of a scanning mobility particle sizing technology with $60 \mathrm{~s}$ time resolutions (Manigrasso et al., 2017a). The NanoScan SMPS is ideal for applications that demand portability like on-road measurements, workplace surveys, field studies, and point source identification. Once again, also in this case, the attention was focused on UFPs, i.e., on size channels from $11.5 \mathrm{~nm}$ to $115.5 \mathrm{~nm}$ (and the first three modes, which are important in the accumulation mode). Further, a Condensation Particle Counter (CPC, model 3007, TSI) was used for measuring particle concentrations in the range $0.01-1 \mu \mathrm{m}$. The particles present in the sample serve as condensation sites for alcohol vapor: after the condensation starts, the particles quickly grow, and an optical detector manages to count the. Finally, a Q-Trak ${ }^{\mathrm{TM}}$ Indoor Air Quality Monitors (model 7575, TSI) was used for determining total VOCs second-by-second. For a better personal exposure evaluation, the probes (anti-electrostatic tubes) were placed on the jacket lapel, on opposite sides for avoiding air vortices that could affect the measurement. A backpack was equipped with all this equipment. This sampling was also performed in July.

\section{Results and Discussion}

Even if the air quality monitoring is a well-known issue and the atmospheric pollutants are well-defined according to the regulations, the dynamic of aerosols is still an interesting and important task. About the inorganic and/or organic composition of PMio and PM2.5 there are a lot of literature, also by the authors of this paper; on the other hand, about the submicron fraction and their relevance for the human health data are still scares due to the difficulties to investigate it. In fact, dedicated equipment is necessary both for monitoring stations and for personal exposure. Further, the dynamic of such fraction is not easy to understand, because of the peculiarity of these particles, as well to effectively understand how the UFPs affect the human health, over the respiratory diseases.

In this way the authors would like to show two different scenarios of sampling and evaluation of submicron fractions and UFPs, particularly. Both scenarios are investigated and discussed according to the number concentration and the behavior of the relative size fractions.

\section{First case study:}

\section{sampling in downtown Rieti}

Table 1 shows the levels of particles in the range 9-340 $\mathrm{nm}$ determined in downtown Rieti along with some statistical information that complete the evaluation. First, the mean total particles of $85470 \# \mathrm{~cm}^{-3}$ can be determined overall the range and the measurements as well. The $95 \%$ percentile is a more interesting information: $68 \%$ of measures of each channel are averagely below the this value with peaks regarding the channel size at $143 \mathrm{~nm}$, where only the $33.5 \%$ of the total measures are below the $95 \%$ percentile, and at $69,8 \mathrm{~nm}$, where $98.8 \%$ of the entire data are below the $95 \%$ percentile. This preliminary information is important for evidencing the different role of particles in such granulometric size. Particles between 5-100 $\mathrm{nm}$ are considered in nucleation Aitken modes and are generally formed by carbon compounds, they come from both fuel engine combustion and lubricating diesel or petrol oils: they show long atmospheric lifetime, are subjected to coagulation processes. The times are short because the particles coagulate easily with other particles to give larger particles; consequently, these particles can better be observed close their sources. On the other hand, particles above 100 $\mathrm{nm}$ (up to $2.5 \mu \mathrm{m}$ ) are in the accumulation mode, generally explain most of the surface area of the aerosol and a substantial part of their mass. The particles of this mode derive mainly from coagulation and aggregation of UFPs, from vapor condensation on particles and from chemical-physical breakdown of larger particles. This mode is important because the particle removal mechanisms are less effective in the relative size range, so that the particles accumulate in the air. 
Ivan Notardonato, Maurizio Manigrasso, Luigi Pierno, Gaetano Settimo, Carmela Protano, Matteo Vitali, Vincenzo Mattei, Stefano Martellucci, Cristina Di Fiore, Paolo Boccia, Pasquale Avino

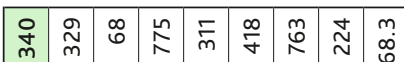

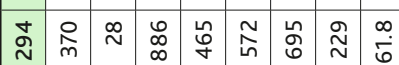

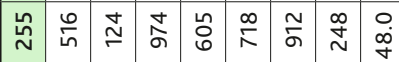
กิ

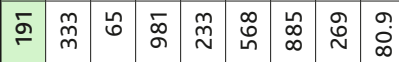

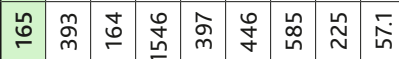

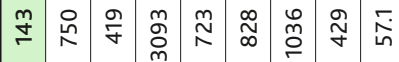

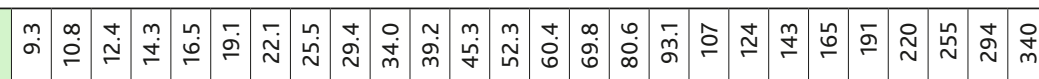

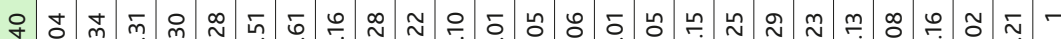

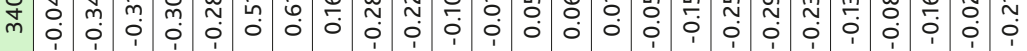

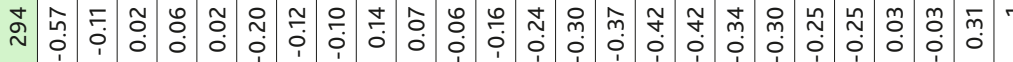

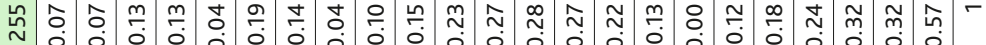

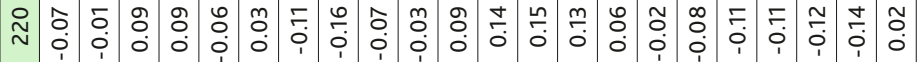

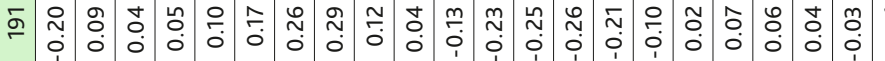

น̂

m

方 $ᄋ$ m

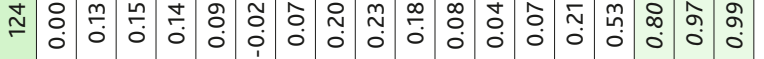

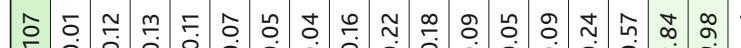

г্்

今

$\frac{\check{\Perp}}{\frac{\pi}{2}}$

0 든

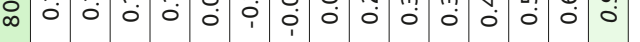

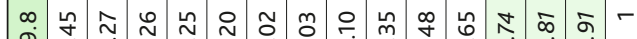

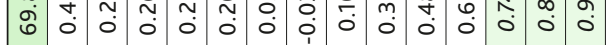

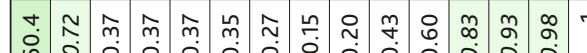

$\begin{array}{llllllllllllllll}0 & 0 & 0 & 0 & 0 & 0 & 0 & 0 & 0 & 0 & 0 & 0 & 0 & 0\end{array}$

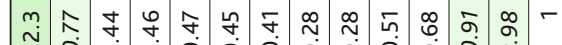

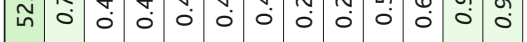

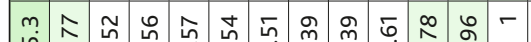

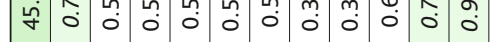

n

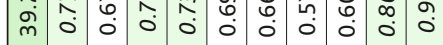

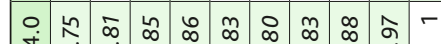

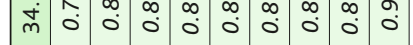

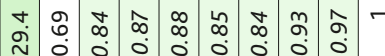

西

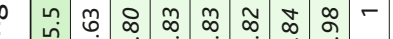

$\begin{array}{lllllllll}n & 0 & 0 & 0 & 0 & 0 & 0 & 0\end{array}$

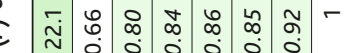

テே

นก $\infty$ ก

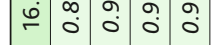

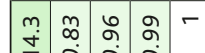

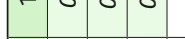

ป்

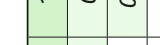

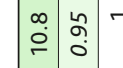

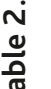

m. 
As a result, residence time is longer than for previous mode as well as for particles above $2.5 \mu \mathrm{m}$ (also in the order of days) and these particles manage to be transported to greater distances (up to kilometers of kilometers). Another important parameter is the variability (calculated as coefficient of variation, $\mathrm{cv} \%$ ): it should be noted that it varies from $155 \%$ for lowest particles, below $10 \mathrm{~nm}$, whereas it decreases up to $16 \%$ for particles between $50-90 \mathrm{~nm}$. This occurrence is also important: the high variability of the particles below 12 $\mathrm{nm}$ means fresh aerosol continuously present in the atmosphere, basically anthropogenic sources, like combustion processes, operating in that area. The low levels found in the range $50-90 \mathrm{~nm}$ are a further confirmation about the beginning of the coagulation process with formation of larger and more stable particles.

A comparison with Rome data (Manigrasso et al, 2019c) collected in downtown $\left(10183 \pm 3810 \# \mathrm{~cm}^{3}\right)$, highlights a less UFP number in downtown Rieti $\left(4,500 \pm 2353 \mathrm{\#} \mathrm{cm}^{-3}\right)$ whereas the particles between 110$560 \mathrm{~nm}$ are higher in Rieti $\left(4402 \pm 398 \#^{\mathrm{cm}^{-3}}\right)$ than those determined in Rome $\left(1722 \pm 698\right.$ cm $\left.^{-3}\right)$. This occurrence could be explained with the different orographic and meteorological conditions of the two sites where the samplings were performed: Rome shows favor conditions for the pollutant dispersion (e.g., more open spaces, wind direction), Rieti is characterized by a small downtown where the buildings are very close between them.

Table 2 shows the relative Pearson's correlation $(r)$ coefficients determined for all the channel sizes: the coefficients reported in italic, i.e. those above 0.7 , evidence a good correlation between the two fractions considered. Still in this case, the correlations are good for nearby dimensional size below $34 \mathrm{~nm}$, meaning that the fresh aerosol is emitted by the same sources, e.g. the autovehicular traffic, and this is the main source affecting the area.

Figure 3 shows the behavior of each aerosol dimensional size in the range 5-107 $\mathrm{nm}$. As it can be seen, the trends are almost similar, confirming the good correlation between the particles in the nucleation mode ("fresh" aerosol). Some peaks are present in correspondence of particles formation due to presence of high autovehicular traffic, for instance.

The authors focused the attention on some characteristic points: particularly, we highlighted three different situations, characterized by highest (times 11:28 and 11:49) and minimum (time 11:56) peaks. Figure 4 shows these three size profiles along with the profile (named "average") obtained by the average of the particle number of each channel size overall the measurements. The profiles evidence a bimodal behavior: a high peak below $10 \mathrm{~nm}$ and another peak pointed out at around $50 \mathrm{~nm}$.

These two peaks are indicators of two different occurrences. The particles below $10 \mathrm{~nm}$ are index of a strong emission located just close the sampling point: particles generated by combustion process, basically. Once formed and suspended in the atmosphere, the particles in the nucleation mode are characterized by Brownian motions: the collisions generated aggregation processes, increasing the particles in the nucleation mode up to the accumulation mode, reaching a maximum around 50-70 $\mathrm{nm}$. These profiles are similar to ones recorded in downtown Rome, even if, of course, the quantitative levels are really different (Avino \& Manigrasso, 2017). Such typical profiles confirm

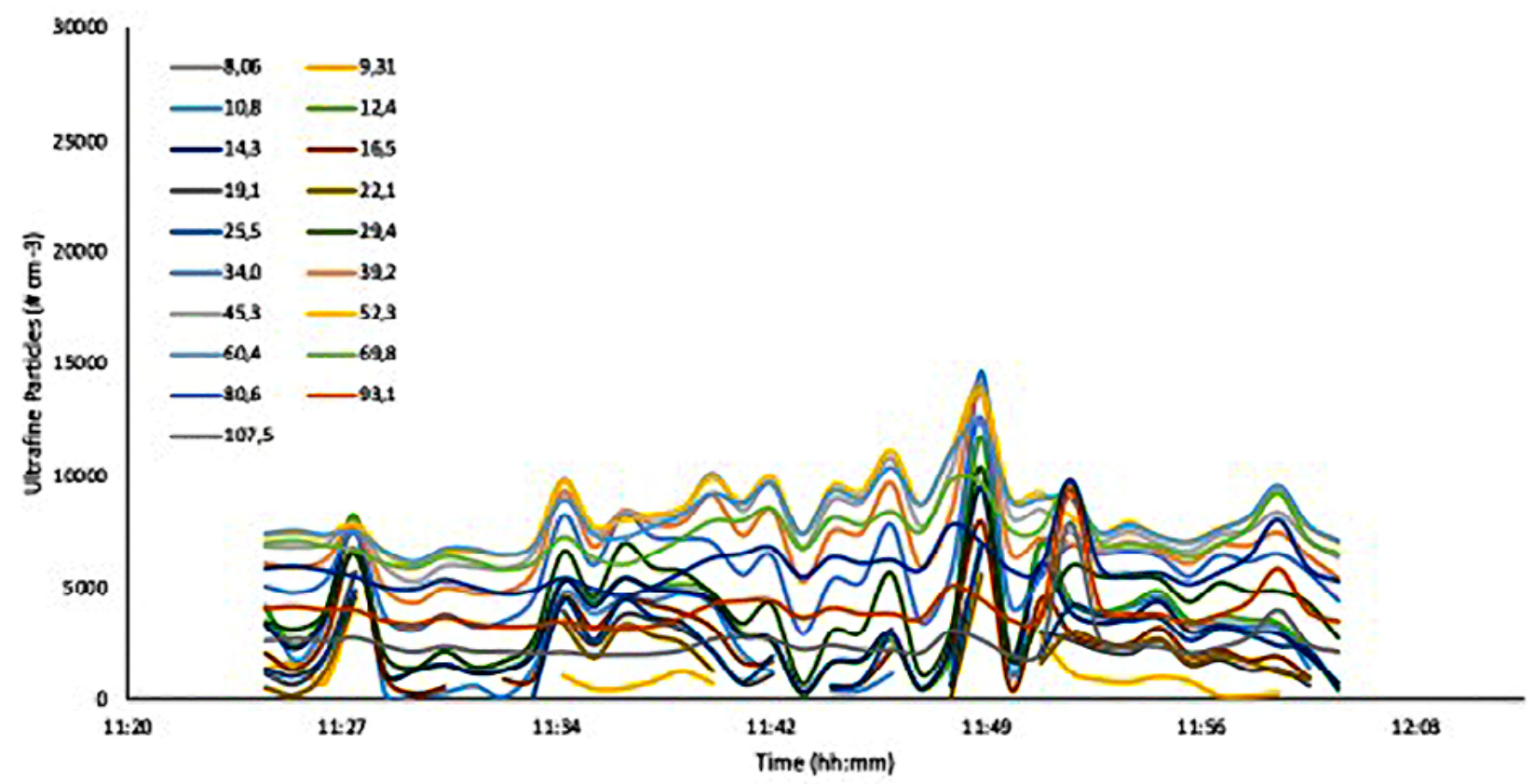

Figure 3. Typical particle distribution profiles $\left(\# \mathrm{~cm}^{-3}\right)$ in the range below $107 \mathrm{~nm}$ in downtown Rieti in the morning 


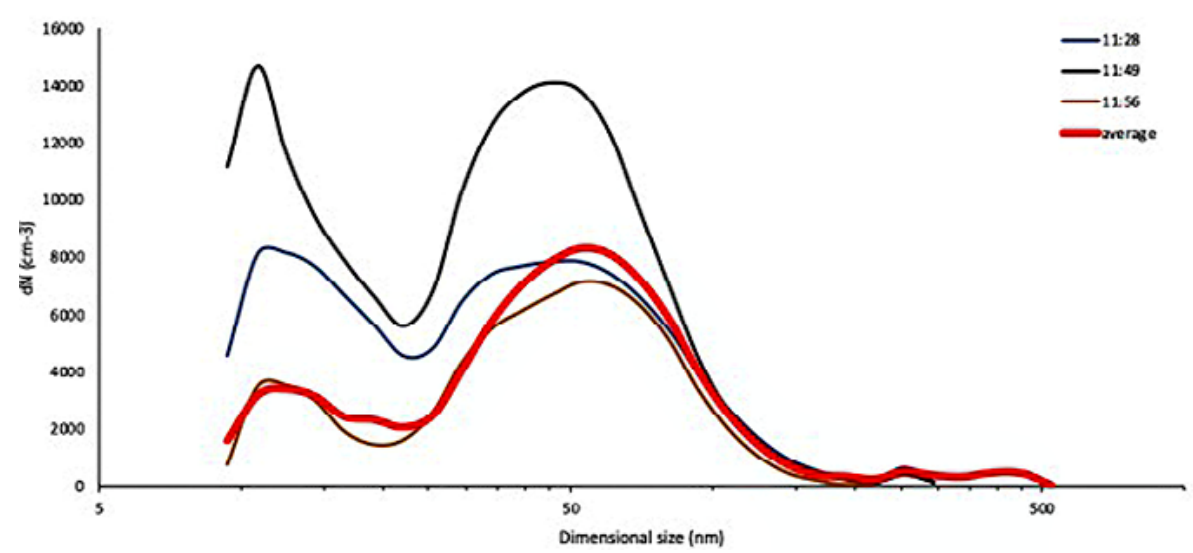

Figure 4. Typical size distribution measured in downtown Rieti at different morning times

that the autovehicular traffic is still the main problem in both big and small cities and it represents an important issue to be solved for improving the air quality. In fact, it should be underlined that this task concerns not only gaseous pollutants but also aerosols, specifically the submicron fraction and Ultrafine Particles as well, which indeed are the new target to be measured.

\section{Second case study:}

\section{walking and breathing around a small city}

The second approach the authors would like to present regards the study of the personal exposure of a person walking along a small town, Venafro, during workdays. Table 3 shows all the levels $\left(\mu \mathrm{g} \cdot \mathrm{m}^{-3}\right)$ of $\mathrm{PM}_{1}$, $\mathrm{PM}_{2.5}, \mathrm{PM}_{4}, \mathrm{PM}_{10}$ and Total PM.

The lines reporting the $95 \%$ percentile and the variability are quite interesting. The first one shows that the $95 \%$ (3196) of the all data (\# samples 3364) are below $44,45,47$ and $53 \mu \mathrm{g} \cdot \mathrm{m}^{-3}$ for the four PM fractions, respectively, whereas only 168 measures (not: secondby-second) range between 44 and $1090 \mu \mathrm{g} \cdot \mathrm{m}^{-3}$ for $\mathrm{PM}_{1}$, for instance. The variability is quite high, ranging from $172 \%$ for $\mathrm{PM}_{1}$ to $202 \%$ for $\mathrm{PM}_{10}$, meaning a continuous and novel particle contribution of these fractions. On the other hand, it should be noted that the
$\mathrm{PM}_{2.5}$ fraction is $86 \%$ of $\mathrm{PM}_{10}$ whereas that $83 \%$ of $\mathrm{PM}_{10}$ is composed by $\mathrm{PM}_{1}$. So, it is more interesting to investigate the submicron fraction which is the most meaningful constituent of $\mathrm{PM}_{10}$. For this aim, preliminarily the particles in the range $10-1000 \mathrm{~nm}$ were counted. Table 3 shows the total particle number recorded during the entire footpath: the submicron par-

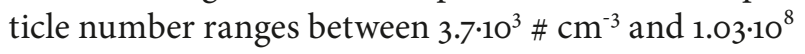
$\# \mathrm{~cm}^{-3}$ but only the $5 \%$ of the overall data are above $44 \cdot 10^{3} \# \mathrm{~cm}^{-3}$. For a comparison, during a similar period, i.e. June/July, in Rome levels ranging between $3.90 \cdot 10^{6}$ and $5.37 \cdot 10^{8}$ were recorded (Avino et al., 2011; Manigrasso et al., 2013; Costabile et al., 2017). Figure 5 shows the submicron fraction trend during the entire path: it could be observed the presence of three maximum peaks between 10:45 and 10:54 a.m. meaning a presence of intense instantaneous emission sources, whereas two similar occurrences, less intense but longer, are evident both at the beginning and at the end of the footpath, meaning a presence of continuous particle emission, i.e. autovehicular traffic.

Following these considerations, the authors approached the analysis of the submicron fraction, expecially in the range 5-365 $\mathrm{nm}$, using the Nanoscan instrumentation.

Table 3. $\mathrm{PM}_{\mathrm{x}}$ levels (as $\mu \mathrm{g} \cdot \mathrm{m}^{-3}$; \# samples 3364) and particle numbers (as submicron fraction) measured using portable instrument during the footpath in Venafro during workdays. Variability (\%) is calculated as coefficient of variation (cv\%).

\begin{tabular}{|l|c|c|c|c|c|c|}
\hline & Particles & PM $_{1}$ & PM $_{2.5}$ & PM $_{4}$ & PM $_{10}$ & Total PM \\
\hline mean & $15293 a$ & 23 & 24 & 25 & 28 & 31 \\
\hline minimum & $3743^{\mathrm{a}}$ & 7 & 8 & 8 & 8 & 8 \\
\hline maximum & $103607051^{\mathrm{a}}$ & 1090 & 1100 & 1130 & 1720 & 2660 \\
\hline $60 \%$ percentile & $11550^{\mathrm{a}}$ & 20 & 21 & 22 & 24 & 24 \\
\hline $80 \%$ percentile & $20240^{\mathrm{a}}$ & 25 & 26 & 27 & 31 & 33 \\
\hline $95 \%$ percentile & $43972^{\mathrm{a}}$ & 44 & 45 & 47 & 53 & 59 \\
\hline standard deviation & $17661^{\mathrm{a}}$ & 40 & 40 & 43 & 57 & 74 \\
\hline variability (\%) & $115^{\mathrm{a}}$ & 172 & 170 & 172 & 202 & 239 \\
\hline
\end{tabular}

a calculated as \# $\mathrm{cm}^{-3}$ 


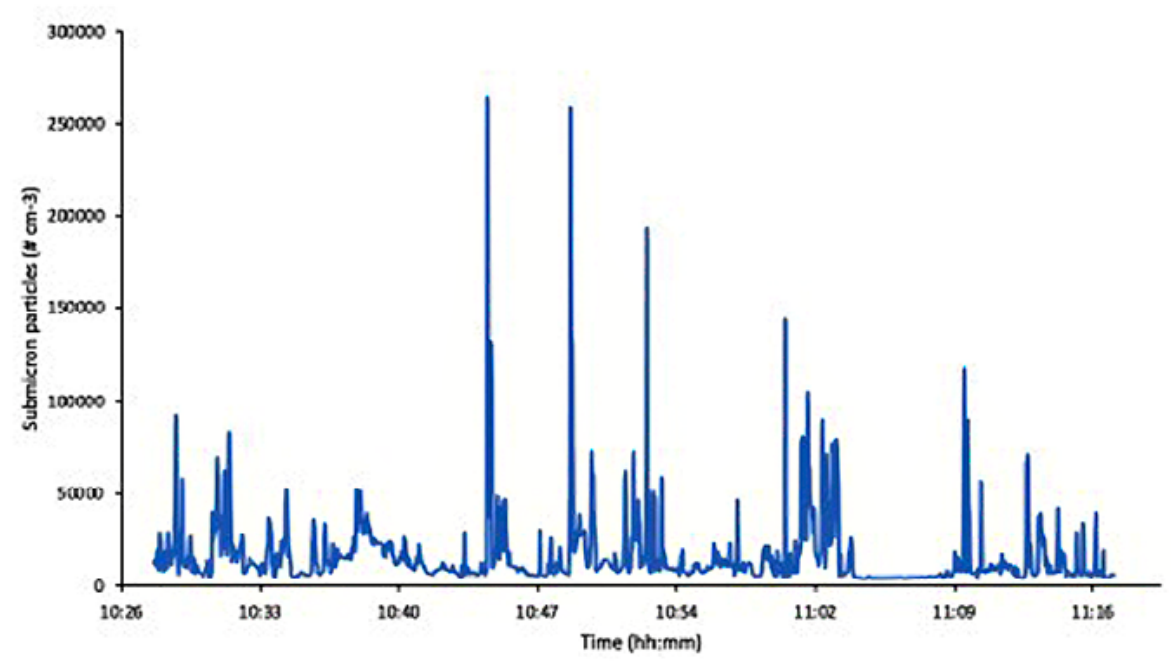

Figure 5. Submicron particles number $\left(\# \mathrm{~cm}^{-3}\right)$ measure during the entire footpath in downtown Venafro

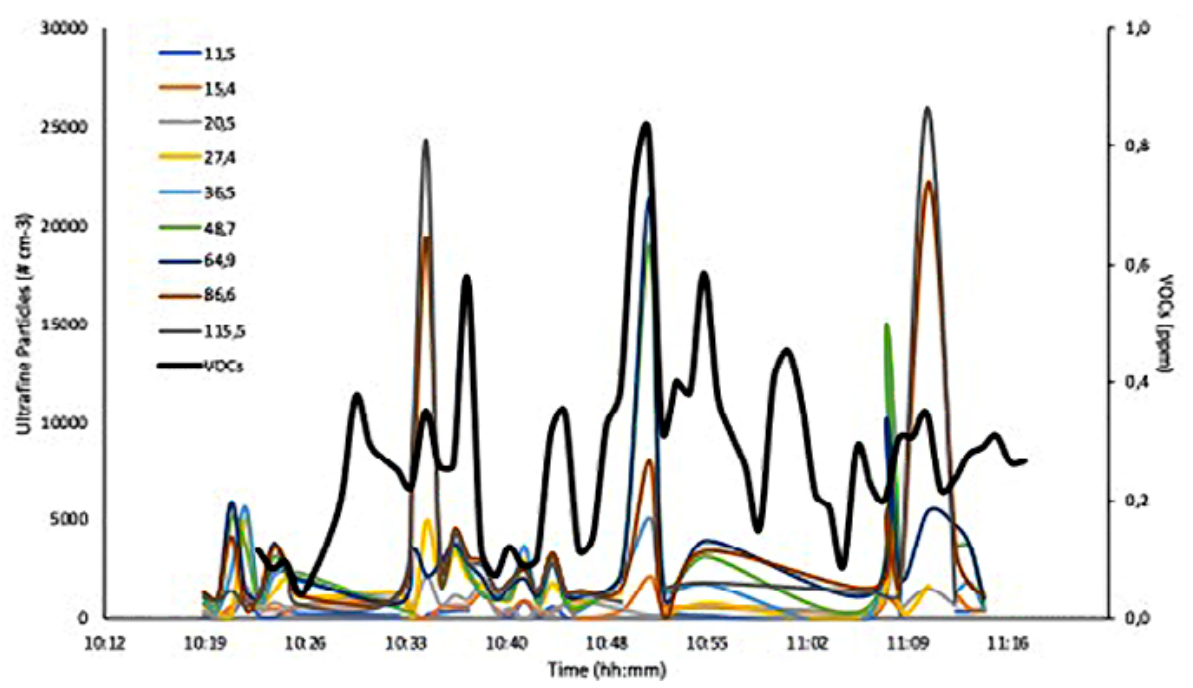

Figure 6. UFP profile $\left(\# \mathrm{~cm}^{-3}\right)$ along with the total VOC (ppm) trend during the entire footpath in Venafro town

Table 4 shows the data collected during the entire sampling, trying to evaluate the personal exposure of a pedestrian around the entire town whereas Table 5 reports the Pearson's correlation coefficients determined between two close sizes (also in this case, the $r$ $>0.7$ are in italic).
A very high variability $(215 \%)$ is recorded for the particles in the size channel $11.5 \mathrm{~nm}$, it means a fresh aerosol continuously emitted by sources but, different from what reported in previous study (Manigrasso et al., 2017a), the variability is always over $101 \%$, except in two cases ( $71 \%$ at $15.4 \mathrm{~nm}$ and $75 \%$ at $20.5 \mathrm{~nm}$ ),

Table 4. Levels $\left(\# \mathrm{~cm}^{-3}\right)$ of particles in the range 5-365 $\mathrm{nm}$ in Venafro town. Variability (\%) is calculated as coefficient of variation (cv\%).

\begin{tabular}{|c|c|c|c|c|c|c|c|c|c|c|c|c|c|}
\hline size $(n m)$ & 11.5 & 15.4 & 20.5 & 27.4 & 36.5 & 48.7 & 64.9 & 86.6 & 115.5 & 154.0 & 205.4 & 273.8 & 365.2 \\
\hline mean & 467 & 584 & 696 & 1563 & 2272 & 3015 & 3180 & 3636 & 3407 & 2181 & 709 & 1066 & 750 \\
\hline $\min$ & 25 & 6 & 2 & 55 & 441 & 357 & 746 & 100 & 639 & 126 & 100 & 71 & 8 \\
\hline $\max$ & 5475 & 2111 & 2138 & 6651 & 14455 & 1895 & 21244 & 22152 & 25867 & 13241 & 4698 & 3152 & 4187 \\
\hline $60 \%$ perc. & 310 & 578 & 671 & 1307 & 2019 & 2616 & 2440 & 2763 & 1797 & 1091 & 320 & 771 & 394 \\
\hline $80 \%$ perc. & 400 & 843 & 996 & 2039 & 2557 & 3605 & 3791 & 3936 & 2733 & 1820 & 574 & 2237 & 532 \\
\hline $95 \%$ perc. & 917 & 1243 & 1722 & 5032 & 5394 & 10033 & 7589 & 12503 & 16741 & 10824 & 3749 & 2968 & 2922 \\
\hline st. dev. & 1005 & 414 & 523 & 1588 & 2651 & 3956 & 3763 & 4756 & 5992 & 3356 & 1225 & 1270 & 1403 \\
\hline variability & 215.3 & 70.9 & 75.1 & 101.6 & 116.7 & 131.2 & 118.4 & 130.8 & 175.9 & 153.8 & 172.8 & 119.1 & 186.9 \\
\hline
\end{tabular}


Table 5. Pearson's correlation coefficients $(r)$ among particles in the range 5-365 nm in Venafro town. Values $>0.7$ are reported in italic.

\begin{tabular}{|c|c|c|c|c|c|c|c|c|c|c|c|c|c|}
\hline 11.5 & 15.4 & 20.5 & 27.4 & 36.5 & 48.7 & 64.9 & 86.6 & 115.5 & 154.0 & 205.4 & 273.8 & 365.2 & \\
\hline \multirow[t]{13}{*}{1} & 0.44 & 0.11 & 0.71 & 0.95 & 0.92 & 0.75 & 0.12 & -0.06 & 0.04 & 0.01 & -0.18 & -0.15 & 11.5 \\
\hline & 1 & 0.08 & 0.41 & 0.45 & 0.72 & 0.71 & 0.01 & -0.34 & -0.29 & 0.01 & 0.52 & 0.83 & 15.4 \\
\hline & & 1 & 0.65 & 0.17 & -0.14 & -0.11 & 0.51 & 0.57 & 0.50 & -0.14 & -0.48 & -0.36 & 20.5 \\
\hline & & & 1 & 0.90 & 0.77 & 0.49 & 0.33 & 0.27 & 0.33 & -0.25 & -0.37 & -0.30 & 27.4 \\
\hline & & & & 1 & 0.76 & 0.55 & 0.53 & 0.06 & 0.28 & 0.05 & 0.18 & 0.54 & 36.5 \\
\hline & & & & & 1 & 0.95 & 0.65 & -0.12 & -0.10 & -0.04 & 0.49 & 0.98 & 48.7 \\
\hline & & & & & & 1 & 0.33 & 0.21 & 0.45 & 0.19 & 0.49 & 0.98 & 64.9 \\
\hline & & & & & & & 1 & 0.98 & 0.94 & 0.24 & 0.36 & 0.91 & 86.6 \\
\hline & & & & & & & & 1 & 0.97 & 0.49 & 0.37 & 0.08 & 115.5 \\
\hline & & & & & & & & & 1 & 0.82 & 0.94 & 0.53 & 154.0 \\
\hline & & & & & & & & & & 1 & 0.98 & 0.53 & 205.4 \\
\hline & & & & & & & & & & & 1 & 0.52 & 273.8 \\
\hline & & & & & & & & & & & & 1 & 365.2 \\
\hline
\end{tabular}

showing a presence of possible different contributions over the combustion processes.

Figure 6 shows the behavior of the UFPs at different sizes related to the total VOCs trend in the same period. As it can be seen, the UFPs, expecially in the range 8o-110 nm, follows the same tendency of VOCs: these related only to combustion processes: this high correlation is important because it shows how the transportation is one of the main contribution affecting the air quality in that area.

Figure 7 confirms what reported above: the aerosol size distributions determined during the maximum

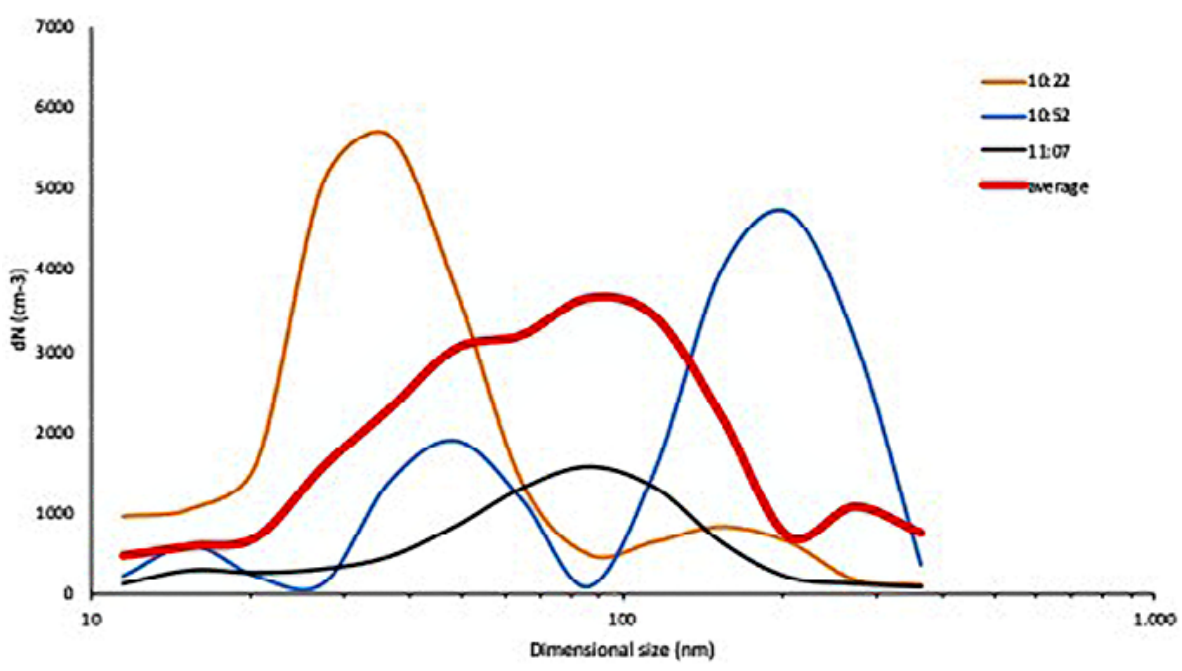

Figure 7. Typical size distribution measured in downtown Venafro at different morning times

compounds are associated with the presence of anthropogenic sources in the area. This statement is also confirmed by the $\mathrm{CO}$ trend measured simultaneously (and reported in the plot), which is an index directly peaks (i.e., at 10:22 and 10:52 a.m.) are typical of an urban area with high autovehicular traffic, due to the presence of two modes at 20-40 nm and 100-120 nm (Avino et al., 2011; Avino \& Manigrasso, 2017).

\section{Conclusions}

The paper would like to review the importance of the submicron fraction, expecially the ultrafine particles, in the air quality monitoring. The studies on this task based on the determination of gaseous pol- lutants and on $\mathrm{PM}_{10}$ and $\mathrm{PM}_{2.5}$, prove themselves to be not sufficient for describing the entire satiation as well as for a correct evaluation of the public health. The submicron particles, which manage to reach the 
deepest part of the human respiratory system (Avino et al., 2013; Manigrasso et al., 2017b), are responsible of different pulmonary, cardiovascular diseases: they should represent the new target in the evaluation of the air quality. In this study the authors re- port two different methodological approach for determining and evaluating the contribution of these fractions to the air quality and the correlation with the anthropogenic sources, first of all, the combustion processes.

\section{Acknowledgements}

The authors wish to thank ALCLI "Giorgio e Silvia", a non-profit association, for their financial support.

\section{References}

Avino, P., Brocco, D., Lepore, L., \& Pareti, S. (2003). Interpretation of atmospheric pollution phenomena in relationship with the vertical atmospheric remixing by means of natural radioactivity measurements (radon) of particulate matter. Annali di Chimica-Rome, 93, 589-594. PMID: 12911151

Avino, P., \& Manigrasso, M., (2008). Ten-year measurements of gaseous pollutants in urban air by an open-path analyzer. Atmospheric Environment, 42, 4138-4148. doi: 10.1016/j.atmosenv.2008.01.024

Avino, P., Casciardi, S., Fanizza, C., \& Manigrasso, M. (2011). Deep investigation of ultrafine particles in urban air. Aerosol and Air Quality Research, 11, 654663. doi: 10.4209/aaqr.2010.10.0086

Avino, P., Lopez, F., \& Manigrasso, M. (2013). Regional deposition of submicrometer aerosol in the human respiratory system determined at 1-s time resolution of particle size distribution measurements. Aerosol and Air Quality Research, 13, 1702-1711. doi: 10.4209/aaqr.2013.06.0189

Avino, P., Protano, C., Vitali, M., \& Manigrasso, M. (2017). Benchmark study on fine-mode aerosol in a big urban area and relevant doses deposited in the human respiratory tract. Environmental Pollution, 216, 530-537. doi: 10.1016/j.envpol.2016.06.005

Avino, P., \& Manigrasso, M. (2017). Dynamic of submicrometer particles in urban environment. Environmental Science and Pollution Research, 24, 13908-13920. doi: 10.1007/s11356-016-6752-8

Borrow, D.J., van Netten, K., Galvin, K.P. (2018). Ultrafine particle recovery using thin permeable films. Frontiers in Chemistry, 6, art. 220. doi: 10.3389/fchem.2018.00220

Buonanno, G., Stabile, L., Avino, P., \& Vanoli, R. (2010). Dimensional and chemical characterization of particles at a downwind receptor site of a wasteto-energy plant. Waste Management, 30, 1325-1333. doi: 10.1016/j.wasman.2009.12.025

Buonanno, G., Stabile, L., Avino, P., \& Belluso, E. (2011). Chemical, dimensional and morphological ultrafine particle characterization from a waste- to-energy plant. Waste Management, 31, 2253-2262. doi: 10.1016/j.wasman.2011.06.017

Buonanno, G., \& Morawska, L. (2015). Ultrafine particle emission of waste incinerators and comparison to the exposure of urban citizens. Waste Management, 37, 75-81. doi: 10.1016/j.wasman.2014.03.008

Carrer, S., Halling-Sørensen, B., \& Bendoricchio, G. (2000). Modelling the fate of dioxins in a trophic network by coupling an ecotoxicological and an Ecopath model. Ecological Modelling, 126, 201-223. doi: 10.1016/s0304-380o(oo)00266-o

Chen, B., \& Zhao, B. (2011). Review of relationship between indoor and outdoor particles: I/O ratio, infiltration factor and penetration factor. Atmospheric Environment, 45, 275-288. doi: 10.1016/j. atmosenv.2010.09.048

Costabile, F., Alas, H., Aufderheide, M., Avino, P., Amato, F., Argentini, S., Barnaba, F., Berico, M., Bernardoni, V., Biondi, R., Calzolai, G., Canepari, S., Casasanta, G., Ciampichetti, S., Conidi, A., Cordelli, E., Ianni, A.D., Liberto, L.D., Facchini, M.C., Facci, A., Frasca, D., Gilardoni, S., Grollino, M.G., Gualtieri, M., Lucarelli, F., Malaguti, A., Manigrasso, M., Montagnoli, M., Nava, S., Padoan, E., Perrino, C., Petralia, E., Petenko, I., Querol, X., Simonetti, G., Tranfo, G., Ubertini, S., Valli, G., Valentini, S., Vecchi, R., Volpi, F., Weinhold, K., Wiedensholer, A., Zanini, G., \& Gobbi, G.P. (2017). First results of the "Carbonaceous Aerosol in Rome and Environs (CARE)" experiment: Beyond current standards for $\mathrm{PM}_{10}$. Atmosphere, 8 , art. 249. doi: 10.339o/atmos8120249

Cyrys, J., Pitz, M., Bischof, W., Wichmann, H. E., \& Heinrich, J. (2004). Relationship between indoor and outdoor levels of fine particle mass, particle number concentrations and black smoke under different ventilation conditions. Journal of Exposure Analysis and Environmental Epidemiology, 14, 275283. doi: $10.1038 /$ sj.jea. 7500317

De Hartog, J.J., Hoek, G., Peters, A., Timonen, K.L., Ibald-Mulli, A., Brunekreef, B., Heinrich, J., Tiittanen, P., van Wijnen, J.H., Kreyling, W., Kulma- 
la, M., \& Pekkanen, J. (2003). Effects of fine and ultrafine particles on cardiorespiratory symptoms in elderly subjects with coronary heart disease - The ULTRA study. American Journal of Epidemiology, 157, 613-623. doi: 10.1093/aje/kwgo21

Diapouli, E., Chaloulakou, A., Mihalopoulos, N., \& Spyrellis, N. (2008). Indoor and outdoor PM mass and number concentrations at schools in the Athens area. Environmental Monitoring and Assessment, 136, 13-20. doi: 10.1007/s10661-007-9724-o

Fernández-Camacho, R., Rodríguez, S., de la Rosa, J., Sánchez de la Campa, A.M., Alastuey, A., Querol, X., González-Castanedo, Y., Garcia-Orellana, I., \& Nava, S. (2012). Ultrafine particle and fine trace metal ( $\mathrm{As}, \mathrm{Cd}, \mathrm{Cu}, \mathrm{Pb}$ and $\mathrm{Zn}$ ) pollution episodes induced by industrial emissions in Huelva, SW Spain. Atmospheric Environment, 61, 507-517. doi: 10.1016/j.atmosenv.2012.08.003

Jiang, B., Xie, Y., Xia, D., \& Liu, X. (2019). A potential source for $\mathrm{PM}_{2.5}$ : Analysis of fine particle generation mechanism in Wet Flue Gas Desulfurization System by modeling drying and breakage of slurry droplet. Environmental Pollution, 246, 249-256. doi: 10.1016/j.envpol.2018.12.001

Johannson, K.A., Balmes, J.R., \& Harold, R. (2015). Air pollution exposure. A novel environmental risk factor for interstitial lung disease? Chest, 147, 11611167. doi: 10.1378/chest.14-1299

Jones, N.C., Thornton, C.A., Mark, D., \& Harrison, R.M. (2000). Indoor/outdoor relationships of particulate matter in domestic homes with roadside, urban and rural locations. Atmospheric Environment, 34, 2603-2612. doi: 10.1016/S13522310(99)00489-6

Kelly, F.J., \& Fussell, J.C. (2019). Improving indoor air quality, health and performance within environments where people live, travel, learn and work. Atmospheric Environment, 200, 90-109. doi: 10.1016/j. atmosenv.2018.11.058

Leung, D.Y.C. (2015). Outdoor-indoor air pollution in urban environment: challenges and opportunity. Frontiers in Environmental Science, 15, art. 69. doi: 10.3389/fenvs.2014.00069

Lia, N., Maesano, C.N., Friedrich, R., Medda, E., Brandstetter, S., Kabesch, M., Apfelbacher, C., Melter, M., Seelbach-Göbel, B., Annesi-Maesano, I., Sarigiannis, D., \& the KUNO-Kids study group. (2019). A model for estimating the lifelong exposure to $\mathrm{PM}_{2.5}$ and $\mathrm{NO}_{2}$ and the T application to population studies. Environmental Research, 178, 108629. doi: 10.1016/j.envres.2019.108629

Maher, B.A., Ahmed, I.A.M., Karloukovski, V., MacLaren, D.A., Foulds, P.G., Allsop, D., Mann, D.M.A., Torres-Jardón, R., \& Calderon-Garciduenas, L. (2016). Magnetite pollution nano- particles in the human brain. Proceedings of the National Academy of Sciences, 113, 10797-10801. doi: 10.1073/ pnas. 1605941113

Manigrasso, M., \& Avino, P. (2012). Fast evolution of urban ultrafine particles: Implications for deposition doses in the human respiratory system. Atmospheric Environment, 51, 116-123. doi: 10.1016/j.atmosenv.2012.01.039

Manigrasso, M., Stabile, L., Avino, P., \& Buonanno, G. (2013). Influence of measurement frequency on the evaluation of short-term dose of sub-micrometric particles during indoor and outdoor generation events. Atmospheric Environment, 67, 130-142. doi: 10.1016/j.atmosenv.2012.10.059

Manigrasso, M., Natale, C., Vitali, M., Protano, C., \& Avino, P. (2017a). Pedestrians in traffic environments: Ultrafine particle respiratory doses. International Journal of Environmental Research and Public Health, 14, art. 288. doi: 10.3390/ijerph14030288

Manigrasso, M., Vernale, C., \& Avino, P. (2017b). Traffic aerosol lobar doses deposited in the human respiratory system. Environmental Science and Pollution Research, 24, 13866-13873. doi: 10.1007/ s11356-015-5666-1

Manigrasso, M., Protano, C., Astolfi, M.L., Massimi, L., Avino, P., Vitali, M., \& Canepari, S. (2019a). Evidences of copper nanoparticle exposure in indoor environments: Long-term assessment, high-resolution field emission scanning electron microscopy evaluation, in silico respiratory dosimetry study and possible health implications. The Science of the Total Environment, 653, 1192-1203. doi: 10.1016/j.scitotenv.2018.11.044

Manigrasso, M., Protano, C., Vitali, M., \& Avino, P. (2019b). Where do ultrafine particles and nanosized particles come from? Journal of Alzheimer's Disease, 68, 1371-139o. doi: 10.3233/JAD-181266

Manigrasso, M., Protano, C., Martellucci, S., Mattei, V., Vitali, M., \& Avino, P. (2019c). Evaluation of the submicron particles distribution between mountain and urban site: contribution of the transportation for defining environmental and human health issues. International Journal of Environmental Research and Public Health, 16, art. 1339. doi:10.339o/ijerph16081339 Marini, S., Buonanno, G., Stabile, L., \& Avino, P. (2015). A benchmark for numerical scheme validation of airborne particle exposure in street canyons. Environmental Science and Pollution Research, 22, 20512063. doi: 10.1007/s11356-014-3491-6

Massey, D., Masih, J., Kulshrestha, A., Habil, M., \& Taneja, A. (2009). Indoor/outdoor relationship of fine particles less than $2.5 \mu \mathrm{m}\left(\mathrm{PM}_{2.5}\right)$ in residential homes locations in central Indian region. Building and Environment, 44, 2037-2045. doi: 10.1016/j. buildenv.2009.02.010 
Monn, Ch., Fuchs, A., Högger, D., Junker, M., Kogelschatz, D., Roth, N., \& Wanner, H.-U. (1997). Particulate matter less than $10 \mu \mathrm{m}\left(\mathrm{PM}_{10}\right)$ and fine particles less than $2.5 \mu \mathrm{m}\left(\mathrm{PM}_{2.5}\right)$ : Relationships between indoor, outdoor and personal concentrations. The Science of the Total Environment, 208, 15-21. doi: 10.1016/Soo48-9697(97)00271-4

Ssebugere, P., Sillanpää, M., Matovu, H., \& Mubiru, E. (2019). Human and environmental exposure to PCDD/Fs and dioxin-like PCBs in Africa: A review. Chemosphere, 223, 483-493. doi: 10.1016/j.chemosphere.2019.02.065

Stabile, L., Buonanno, G., Avino, P., Frattolillo, A., \& Guerriero, E. (2018). Indoor exposure to particles emitted by biomass-burning heating systems and evaluation of dose and lung cancer risk received by population. Environmental Pollution, 235, 65-73. doi: 10.1016/j.envpol.2017.12.055

Wang, G., Bai, X., Wu, C., Li, W., Liu, K., \& Kiani, A. (2018). Recent advances in the beneficiation of ultrafine coal particles. Fuel Processing Technology, 178, 104-125. doi: 10.1016/j.fuproc.2018.04.035

Wichmann, H.E., Spix, C., Tuch, T., Wölke, G., Peters, A., Heinrich, J., Kreyling, W.G., \& Heyder, J. (2009).
Daily mortality and fine and ultrafine particles in Erfurt, Germany part I: role of particle number and particle mass. Research Report (Health Effects Institute), 98, 87-94. PMID: 11918089

World Health Organization - WHO. (2013a). Health risks of air pollution in Europe - HRAPIE project: recommendations for concentration-response functions for cost-benefit analysis of particulate matter, ozone and nitrogen dioxide. Available online at: http://www.euro.who.int/__data/ assets/ pdf_file/ooo6/238956/Health_risks_air_pollution_ HRAPIE_project.pdf.

World Health Organization - WHO. (2013b). Review of evidence on health aspects of air pollution - REVIHAAP project: final technical report. Available online at: http://www.euro.who.int/_data/assets/ pdf_file/ooo4/193108/REVIHAAP-Final-technical-report-final-version.pdf.

Wright, L.P., Zhang, L., Cheng, I., Aherne, J., \& Wentworth, G.R. (2018). Impacts and effects indicators of atmospheric deposition of major pollutants to various ecosystems - A review. Aerosol and Air Quality Research, 18, 1953-1992. doi: 10.4209/ aaqr.2018.03.0107 